\title{
İskemik inmede ekokardiyografi bulgularının inme şiddeti, hemorajik transformasyon ve kısa dönem prognoz ile ilişkisi
}

\author{
Relationship between echocardiography results with stroke severity, hemorrhagic \\ transformation and short-term prognosis in ischemic stroke
}

Fettah Eren, Aydın Yıldoğan, Güllü Eren, Ayşegül Demir, Kenan Demir

Gönderilme tarihi:09.02.2020

Kabul tarihi:08.06.2020

\section{Özet}

Amaç: İskemik inmelerin \%20'sinde etiyolojide kardiyak emboliler vardır. Özellikle genç hastalarda bu oran daha yüksektir. Kardiyak hastalıklar inmede en önemli risk faktörlerindendir. Bu nedenle sol kalp ölçümlerinin inme şiddeti ve prognoz ile ilişkisi araştııılmıştır.

Gereç ve yöntem: Çalışmaya 70 iskemik inme hastası alındı. Özürlülük durumu, National Institutes of Health Stroke Scale (NIHSS) ve modifiye Rankin skalası (mRS) ile değerlendirildi. 72 saat içinde transtorasik ekokardiyografi (TTE) yapıldı. NIHSS skoruna göre 0-7 hafif, 8-16 orta ve 16 üzeri ağır şiddette inme olarak gruplandıııldı. mRS 0-2 iyi, 2 üzerinde kötü fonksiyonel durum olarak değerlendirildi. Bir aylık süredeki NIHSS farkları belirlenip gruplandırıldı. Veriler SPSS Windows 21.0 sürümü ile değerlendirildi.

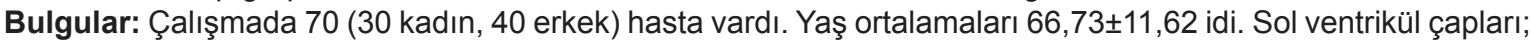
diyastol sonu $4,71 \pm 0,65$, sistol sonu $3,02 \pm 0,82$, diyastolik interventriküler septum $1,11 \pm 0,18$, diyastolik posterior duvar $1,07 \pm 0,16$ santimetre $(\mathrm{cm})$ idi. Ejeksiyon fraksiyonu $55,58 \pm 8,02$ idi. Sol atriyum $3,81 \pm 0,70$ ve aortik anülüs $3,05 \pm 0,49 \mathrm{~cm}$ çapında idi. Başvuru NIHSS skoru yüksek olan gruplarda sol ventrikül sistol ve diyastol sonu çapı daha yüksekti $(p=0,01)$. Diğer TTE bulguları arasında fark yoktu $(p>0,05)$. Hemorajik transformasyon, birinci ayda bakılan NIHSS skoru ve mRS ile TTE ölçümleri arasında ilişki yoktu $(p>0,05)$.

Sonuç: Başlangıçtaki inme dizabilite şiddeti ile sol ventrikül sistol ve diyastol sonu çapı ilişkilidir. İskemik inmede TTE bulguları ile prognoz ve hemorajik transformasyon arasında ilişki yoktur.

Anahtar kelimeler: İskemik inme, transtorasik ekokardiyografi, özürlülük.

Eren F, Yıldoğan A, Eren G, Demir A, Demir K. İskemik inmede ekokardiyografi bulgularının inme şiddeti, hemorajik transformasyon ve kısa dönem prognoz ile ilişkisi. Pam Tıp Derg 2020;13:587-592.

\begin{abstract}
Purpose: Cardiac embolism is $20 \%$ in etiology of ischemic strokes. This rate is higher especially in young patients. Cardiac diseases are the most important risk factors in stroke. Therefore, the relationship between left cardiac measurements with stroke severity and prognosis was investigated.

Materials and methods: Seventy ischemic stroke patients were included to the study. Disability was assessed by National Institutes of Health Stroke Scale (NIHSS) and modified Rankin scale (mRS). Transthoracic echocardiography (TTE) was made within 72 hours. According to NIHSS, 0-7 mild, 8-16 moderate and over 16 severe stroke were grouped. mRS was evaluated as 0-2 good and over 2 poor state. Differences of NIHSS and mRS within one month were determined and grouped. The results were evaluated with SPSS Windows 21.0 version.

Results: Seventy patients (30 females, 40 males) were included to study. The mean age was $66.73 \pm 11.62$ years. Left ventricular diameters was end-diastolic $4.71 \pm 0.65$, end-systolic $3.02 \pm 0.82$, diastolic interventricular septum $1.11 \pm 0.18$ and diastolic posterior wall $1.07 \pm 0.16$ centimeters $(\mathrm{cm})$. The ejection fraction was $55.58 \pm 8.02$. Left atrium was $3.81 \pm 0.70$ and aortic annulus was $3.05 \pm 0.49 \mathrm{~cm}$ diameter. Left ventricular systolic and enddiastolic diameter were higher in the groups with high NIHSS score $(p=0.01)$. There was no difference between the other TTE results $(p>0.05)$. There was no correlation between hemorrhagic transformation, NIHSS and mRS score with TTE measurements at 1 month $(p>0.05)$.

Conclusion: Initial stroke disability severity is associated with left ventricular systolic and end-diastolic diameter. There is no correlation between TTE results with prognosis and hemorrhagic transformation in ischemic stroke.
\end{abstract}

Fettah Eren, Uzm. Dr. Sağlık Bilimleri Üniversitesi, Konya Eğitim ve Araştırma Hastanesi, Nöroloji Kliniği, Konya, Türkiye, e-posta: dreren42@ hotmail.com (orcid.org/0000-0001-6834-0827) (Sorumlu Yazar)

Aydın Yıldoğan, Arş. Gör. Selçuk Üniversitesi Tıp Fakültesi, Nöroloji Anabilim Dalı, Konya, Türkiye, e-posta: ta_lip_38@hotmail.com (orcid. org/0000-0002-9482-6203)

Güllü Eren, Arş. Gör. Necmettin Erbakan Üniversitesi, Meram Tıp Fakültesi, Halk Sağlığı Anabilim Dalı, Konya, Türkiye, e-posta: gulludogru7@ gmail.com (orcid.org/0000-0003-4033-7946)

Ayşegül Demir, Uzm. Dr. Sağlık Bilimleri Üniversitesi, Konya Eğitim ve Araştırma Hastanesi, Nöroloji Kliniği, Konya, Türkiye, e-posta: D_ Raysegul@hotmail.com (orcid.org/0000-0002-5444-9837)

Kenan Demir, Doç. Dr. Selçuk Üniversitesi Tıp Fakültesi, Kardiyoloji Anabilim Dalı, Konya, Türkiye, e-posta: drkenan76@yahoo.com (orcid. org/0000-0003-0037-0549) 
Key words: Ischemic stroke, transthoracic echocardiography, disability.

Eren F, Yildogan A, Eren G, Demir A, Demir K. Relationship between echocardiography results with stroke severity, hemorrhagic transformation and short-term prognosis in ischemic stroke. Pam Med J 2020;13:587592.

\section{Giriş}

İskemik inme, beynin belirli bir bölgesinin kan akınımın kesintiye uğraması sonucu meydana gelen ve akut olarak çeşitli nörolojik semptomlar ile ortaya çıkan bir hastalıktır [1]. Koroner arter hastalığı ve kanserlerden sonra bazı kaynaklara göre üçüncü, bazılarına göre dördüncü en sık ölüm sebebidir. Özürlülüğe sebep olan hastalıklar listesinde ise travmadan sonra ikinci sırada yer almaktadır [2]. Bu kadar sık olması ciddi toplumsal, ailesel ve ekonomik sorunları da beraberinde getirmektedir. Bu nedenle etiyolojik etmenlerin iyi değerlendirilmesi gerekmektedir.

Kardiyak kökenli inmeler, tüm inmelerin yaklaşık \%20'sini oluşturmaktadır [3, 4]. Bunların yarısında etiyolojide aritmi vardır. Aritmiler içerisinde ise en sık atriyal fibrilasyon (AF) yer almaktadır. Tanısında kısa ve uzun çekim elektrokardiyografiler kullanılmaktadır. Aritmi dışı kardiyak hastalıkların ve kriptojenik inmelerin değerlendirilmesinde ise ekokardiyografi gerekmektedir. Transözofageal ekokardiyografi (TEE) kardiyoembolik inmede intrakardiyak ve sol atriyal trombüsü dışlamakta daha duyarlıdır. Ancak transtorasik ekokardiyografi (TTE) daha kolay ulaşılabilen ve uygulanabilen bir inceleme yöntemidir [5].

Daha önce yapılan çalışmalarda kardiyak ölçümlerin inme şiddeti ile iliş̧ili olabileceği gösterilmiştir. Ayrıca bu ölçümler ile inme prognozunun da öngörülebileceği belirtilmiştir. Özellikle sol ventrikül çaplarının ve sol ventrikül fonksiyonlarının iskemik inme ile ilişki olabileceği düşünülmektedir [6]. Bu şekilde prognostik faktörlerin belirlenmesi hastalığın önlenmesinde ve tedavi planlamasında önemlidir [7]. Bu nedenle iskemik inmede sol ventrikül ve sol atriyum ölçümlerinin inme şiddeti, inme prognozu, hemorajik transformasyon ile ilişkisinin değerlendirilmesi amaçlanmıştır.

\section{Gereç ve yöntem}

$\mathrm{Bu}$ çalışma iskemik inme tanısı ile takip edilen hastalar üzerinde yapıldı. TTE ile sol ventrikül ve atriyum ölçümlerinin inme şiddeti ve iyileşme süreci ile ilişkisi değerlendirildi. Çalışma için Selçuk Üniversitesi Tıp Fakültesi Klinik Araştırmalar Etik Kurulu'ndan yerel etik onayı alındı.

Çalışmaya Mart 2017 ile Haziran 2019 tarihleri arasında iskemik inme tanısı ile takip edilen 70 hasta alındı. Semptom-kapı zamanı 0-36 saat olan hastalar retrospektif olarak değerlendirildi. Difüzyon ağırıklı beyin manyetik rezonans görüntüleme (MRG) ile iskemik inme tanısı doğrulandı. Eş zamanlı çekilen beyin bilgisayarlı tomografi (BBT) ile intraserebral hemoraji ekarte edildi. Sol kalp ölçümlerini etkileyebilecek hastalıkları olan hastalar çalışmaya alınmadı. Kontrolsüz hipertansiyon $(\mathrm{HT})$, hiperlipidemi, diyabetes mellitus (DM), kalp kapak değişimi, ileri derecede kalp kapak hastalığı, koroner arter hastalığı olan, koroner arter bypass, pulmoner hipertansiyon, kardiyomiyopati, aort stenozu, kardiyak aritmi öyküsü olan, 18 yaş altı ve 85 yaş üzeri hastalar çalışma dışı bırakıldı. Ayrıca konjenital beyin anomalisi, kitlesel beyin lezyonu olan, rekürren inme, hemorajik inme, serebral enfektif hastalık geçiren, taburculuktan sonra 1. ayda kontrole gelmeyen ve BBT çekilmeyen hastalar da çalışmayadahiledilmedi. Hastalarınyaş, cinsiyet, başlangıç semptomu, sahip olduğu hastalıklar, kullanmakta olduğu ilaçlar sorgulandı. Bilinç bozukluğu, motor, duyusal, görsel ve kraniyal sinir semptomları değerlendirildi. Anterior ve/ veya posterior dolaşım oklüzyonu ayrımına BBT, difüzyon MRG ve klinik bulgular ile birlikte karar verildi. Rutin elektrokardiyografi ve yirmi dört saat holter elektrokardiyografi ile atriyal fibrilasyon araştıııldı. Semptomların başlanmasından sonra ilk 72 saat içinde hastalara 1-5 $\mathrm{MHz}$ transduser kullanılarak Philips CX50 xMATRIX cihazı ile TTE yapıldı. Bütün ölçümler çalışma dizaynından haberi olmayan aynı kardiyolog tarafından yapıldı. Sol ventrikül diyastol sonu çapı (normal aralık (NA): 3,8-5,6 santimetre $(\mathrm{cm})$ ), sistol sonu çapı (NA: 2,0-4,1 cm), diyastolik interventriküler septum çapı (NA: 0,5-1,1 cm), diyastolik posterior duvar 
çapı (NA: 0,7-1,1 cm) ve ejeksiyon fraksiyonu (EF) (NA: >\%55) ölçüldü. Sol atriyum (NA: 1,9$4,0 \mathrm{~cm}$ ) ve aortik anülüs çapı (NA: 2,0-3,7 cm) değerlendirildi.

Hastanede yatış sürecinde klinik nörolojik durumda bozulma olması halinde acil olarak ve taburculuktan sonra 1. ayda poliklinik kontrolünde rutin olarak BBT ile parankimal lezyon ve hemorajik transformasyon durumu değerlendirildi. Başvuruda ve 1. ayda inme şiddeti ve fonksiyonel durumu değerlendirmek için National Institutes of Health Stroke Scale (NIHSS) ve modifiye Rankin skalası (mRS) kullanıldı [8, 9]. Hastalar NIHSS sonuçlarına göre 0-7 hafif, 8-16 orta ve 16 üzeri ağır şiddette inme olarak gruplandırıldı. mRS sonuçlarına göre 0-2 puan iyi, 2 puan üzeri kötü fonksiyonel sonlanım olarak değerlendirildi. Bir aylık süredeki NIHSS puan farkı hesaplandı. Pozitif fark klinik kötüleşme, 0-3 puan azalma hafif düzelme, 3 puan üzeri azalma belirgin düzelme olarak kabul edildi. Tüm bu veriler sonucunda hastalar gruplara ayrıldı. Gruplar kendi içerisinde TTE bulgularına göre karşılaştırıldı.

Verilerin analizi için SPSS 21.0 Package Software (Statistical Package for the Social Sciences Inc.; Armonk, NY, ABD) analiz programı kullanıldı. Normallik analizi Kolmogorov Smirnov testi ile yapıldı. Veriler sayı, yüzde, ortalama \pm standart sapma ve minimum-maksimum değerler ile ifade edildi. Numerik veriler arası ilişki Spearman's Korelasyon testi ile değerlendirdi. Ortalamaların karşılaştırılmasında bağımsız örneklem $T$, Kruskal Wallis ve Mann Whitney $U$ testleri kullanıldı. $r$ değeri=0,26-0,49: zayıf ve 0,500,69: orta korelasyon olarak kabul edildi. Sonuçlar \%95'lik güven aralığında, anlamlılık $p<0,05$ düzeyinde değerlendirildi.

\section{Bulgular}

Çalışmaya $30(\% 42,9)$ kadın ve $40(\% 57,1)$ erkek olmak üzere toplam 70 hasta alındı. Yaş ortalaması 66,73 $\pm 11,62(31-84)$ yıldı. Hastaların 23 (\%32,9)'ü bilinç bozukluğu, 31 (\%44,3)'i kas gücü kaybı, 38 (\%54,3)'i duyu bozukluğu, 14 (\%20)'ü serebellar semptomlar, 7 (\%10)'si vizüel semptomlar ve 22 (\%31,4)'si kraniyal nöronal semptomlar ile başvurdu. Hastaların $48(\% 68,6)$ 'inde anterior ve $22(\% 31,4)$ 'sinde posterior vasküler alanlarda iskemi belirlendi.

NIHSS skoru ortalaması başvuruda 9,31 $\pm 4,21$ (3-19) iken birinci aydaki takipte $6,65 \pm 3,83$ (1-17) idi. mRS başvuruda 3,20 1,05 (1-5) iken birinci ayda 2,45 $\pm 1,27 \quad(0-4)$ idi. Hastaların $5(\% 7,1)$ 'inde serebral hemorajik transformasyon belirlendi. Hastalar gruplara ayrıldığında başvuruda $24(\% 34,3)$ hastada hafif, $36(\% 51,4)$ hastada orta, $10(\% 14,3)$ hastada ağır şiddette inme vardı. Birinci ayda $49(\% 70)$ hastada hafif, $18(\% 25,7)$ hastada orta, $3(\% 4,3)$ hastada ağır şiddette inme vardı. Başvuruda $19(\% 27,1)$ hastada iyi ve $51(\% 72,9)$ hastada kötü fonksiyonel durum saptandı. Birinci ayda $36(\% 51,4)$ hastada iyi ve $34(\% 48,6)$ hastada kötü fonksiyonel durum saptandı. Bir ay içindeki NIHSS farkı incelendiğinde hastaların 7 (\%10)'sinde klinik kötüleşme, 43 (\%61,4)'ünde hafif ve $20(\% 28,6)$ 'sinde belirgin düzelme olduğu görüldü (Tablo 1).

TTE sonucunda: sol ventrikül diyastol sonu çapı $4,71 \pm 0,65(3,5-8,0) \mathrm{cm}$, sistol sonu çapı $3,02 \pm 0,82(2,1-7,2) \mathrm{cm}$, diyastolik interventriküler septum çapı $1,11 \pm 0,18(0,8-1,7)$ $\mathrm{cm}$, diyastolik posterior duvar çapı $1,07 \pm 0,16$ $(0,8-1,7) \mathrm{cm}$ idi. EF: 55,58 $\pm 8,02$ (52-66) olarak ölçüldü. Sol atriyum çapı $3,81 \pm 0,70(2,4-6,5) \mathrm{cm}$ ve aortik anülüs çapı $3,05 \pm 0,49(2,1-4,5) \mathrm{cm}$ idi.

Başvuruda NIHSS skoru yüksek olan gruplarda sol ventrikül diyastol ve sistol sonu çapı daha büyüktü $(p=0,01)$. NIHSS skoru arttıkça sol ventrikül diyastol ve sistol sonu çapı büyümekteydi ( $p=0,01 ; r=0,51)$. İnterventriküler septum çapı, diyastolik posterior duvar çapı, EF, sol atriyum çapı ve aortik anülüs çapı belirlenen özürlülük grupları arasında benzerdi (sırasıyla $p=0,85 ; p=0,88 ; p=0,20 ; p=0,71 ; p=0,47$ ) (Tablo $2)$. Birinci ayda inme şiddeti ve fonksiyonel durum grupları arasında TTE ölçümleri benzerdi $(p>0,05)$. Ayrıca hemorajik transformasyon ve klinik düzelme grupları ile TTE ölçümleri arasında fark yoktu $(p>0,05)$. 
Tablo 1. Başvuruda ve birinci ayda inme şiddeti ve fonksiyonel durum gruplarına göre hasta sayı ve oranları

\begin{tabular}{|c|c|c|c|c|c|c|}
\hline & \multicolumn{2}{|c|}{ Hafif inme şiddeti } & \multicolumn{2}{|c|}{ Orta inme şiddet } & \multicolumn{2}{|c|}{ Ağır inme şiddet } \\
\hline & $\mathbf{n}$ & $\%$ & $\mathbf{n}$ & $\%$ & n & $\%$ \\
\hline \multicolumn{7}{|l|}{ NIHSS } \\
\hline Başvuruda & 24 & 34,3 & 36 & 51,4 & 10 & 14,3 \\
\hline Birinci ayda & 49 & 70 & 18 & 25,7 & 3 & 4,3 \\
\hline
\end{tabular}

\section{lyi fonksiyonel durum Kötü fonksiyonel durum}

mRS

$\begin{array}{lllll}\text { Başvuruda } & 19 & 27,1 & 51 & 72,9 \\ \text { Birinci ayda } & 36 & 51,4 & 34 & 48,6\end{array}$

n: sayı, \%: yüzde, NIHS: National Institutes of Health Stroke Scale, mRS: modifiye Rankin skalası

Tablo 2. İnme başlangıcında özürlülük gruplarına göre transtorasik ekokardiyografi bulguları

\begin{tabular}{|c|c|c|c|c|}
\hline & $\begin{array}{l}\text { NIHSS (0-7) } \\
\text { Hafif }(n=24)\end{array}$ & $\begin{array}{l}\text { NIHSS }(8-16) \\
\text { Orta }(n=36)\end{array}$ & $\begin{array}{l}\text { NIHSS (16 üstü) } \\
\text { Şiddetli }(n=10)\end{array}$ & \\
\hline & $\begin{array}{l}\text { Ortalama } \pm S D \\
\text { (min-maks) }\end{array}$ & $\begin{array}{l}\text { Ortalama } \pm S D \\
\text { (min-maks) }\end{array}$ & $\begin{array}{l}\text { Ortalama } \pm S D \\
\text { (min-maks) }\end{array}$ & $p$ değeri \\
\hline \multicolumn{5}{|l|}{ Sol ventrikül $(\mathrm{cm})$} \\
\hline Diyastol sonu & $\begin{array}{l}4,50 \pm 0,43(3,9-5,5) \\
2,76 \pm 0,61\end{array}$ & $\begin{array}{l}4,70 \pm 0,56 \\
(3,5-6,3)\end{array}$ & $\begin{array}{l}5,2 \pm 1,05 \\
(4,2-8,0)\end{array}$ & $0,01^{*}$ \\
\hline Sistol sonu & $\begin{array}{l}(2,1-4,3) \\
1,10 \pm 0,18\end{array}$ & $\begin{array}{l}3,05 \pm 0,66 \\
(2,1-4,8)\end{array}$ & $\begin{array}{l}3,56 \pm 1,41 \\
(2,2-7,2)\end{array}$ & $0,01^{*}$ \\
\hline IV septum & $\begin{array}{l}(0,8-1,6) \\
1,05 \pm 0,13\end{array}$ & $\begin{array}{l}1,13 \pm 0,19 \\
(0,9-1,7)\end{array}$ & $\begin{array}{l}1,10 \pm 0,17 \\
(0,9-1,3)\end{array}$ & 0,85 \\
\hline Posterior çap & $(0,8-1,4)$ & $\begin{array}{l}1,08 \pm 0,18 \\
(0,8-1,7)\end{array}$ & $\begin{array}{l}1,08 \pm 0,16 \\
(0,9-1,3)\end{array}$ & 0,88 \\
\hline $\mathrm{EF}(\%)$ & $\begin{array}{l}57,0 \pm 4,10 \\
(52-66)\end{array}$ & $\begin{array}{l}55,25 \pm 4,31 \\
(52-63)\end{array}$ & $\begin{array}{l}53,40 \pm 2,76 \\
(52-61)\end{array}$ & 0,20 \\
\hline Sol atriyum $(\mathrm{cm})$ & $\begin{array}{l}3,73 \pm 0,63 \\
(2,4-4,9)\end{array}$ & $\begin{array}{l}3,78 \pm 0,60 \\
(5,6-5,2)\end{array}$ & $\begin{array}{l}4,15 \pm 1,13 \\
(2,8-6,5)\end{array}$ & 0,71 \\
\hline Aortik anülüs (cm) & $\begin{array}{l}2,93 \pm 0,4 \\
(2,2-3,6)\end{array}$ & $\begin{array}{l}3,07 \pm 0,47 \\
(2,1-4,2)\end{array}$ & $\begin{array}{l}3,25 \pm 0,67 \\
(2,3-4,5)\end{array}$ & 0,47 \\
\hline
\end{tabular}

IV: interventriküler, cm: santimetre, \%: yüzde, NIHSS: National Institutes of Health Stroke Scale, SD: standart sapma, min: minimum, maks: maksimum

\section{Tartışma}

İskemik inme, oldukça sık görülen, mortalite ve özürlülük potansiyeli yüksek olan bir hastalıktır. Hastalığın tanı ve tedavisinde çok önemli gelişmeler yaşanmasına rağmen en etkili tedavi basamağını birincil ve ikincil koruma yöntemleri oluşturur $[10,11]$. Bu nedenle inme etiyolojisinde bulunan risk faktörlerinin belirlenmesi, prognozun tespit edilip uygun tedavi yöntemlerinin sağlanması gerekmektedir. İnme şiddetine ve prognoza karar vermek için birçok biyokimyasal, klinik, elektrofizyolik ve radyolojik belirteç kullanılmaktadır [12-14].

Sol atriyum çapı ile inme şiddeti ve prognozu arasındaki ilişkinin değerlendirildiği çalışmalarda oldukça farklı sonuçlar vardır. Bazı çalışmalar sol atriyum çapının iskemik inme için risk oluşturabileceğini ve inme 
prognozunu öngörmede kullanılabileceğini göstermiştir. Bu çaptaki genişlemenin trombüs oluşumunu kolaylaştırdığı ve inme şiddetini artırdığı belirtilmektedir [15, 16]. Ancak ölçüm yönteminin nasıl olması gerektiği tartışmalıdır [17]. Sol atriyum çapı kişilerin yapısal özellikleri ve eşik eden hastalıkları ile de yakından ilişkilidir. Sol atriyum genişliğinin AF ile de ilişkili olabildiği ve aritmi taranmasının önemli olduğu vurgulanmaktadır [18, 19]. Bizim çalışmamızda ölçümleri etkiyebilecek hastalıklar dışlanmasına rağmen sol atriyum çapı ile inme şiddeti ve prognozu arasında ilişki saptanmamıştır.

EF ile inme şiddeti ve prognoz ilişkisinin değerlendirildiği çalışmalara bakıldığında, düşük EF değeri olan hastaların başvuruda, 24. saatte ve 7. günde NIHSS skorlarının daha yüksek olduğu belirlenmiştir. Yine EF değeri düşük olan hastaların 7. gün ve 3 . aydaki $\mathrm{mRS}$ değerlerinin daha yüksek olduğu saptanmıştır [20]. EF ile serebral iskemik alan hacminin ilişkili olduğu, EF düştükçe iskemi alanının arttığı gösterilmiştir [20, 21]. Ancak bazı çalışmalar ise EF düşüklüğü ile inme şiddeti ve prognozun ilişkili olmadığını belirtmektedir. Ancak bu ilişkinin NIHSS ve lipid profili ile birleştirilerek açıklanabileceği vurgulanmıştır [22]. Bizim çalışmamızda hem başvuruda hem de birinci ayda inme özürlülük durumu ile EF değerinin ilişkili olmadığı gösterilmiştir. Bu durum EF, NIHSS skoru ve kan lipid düzeyinin birlikte değerlendirilmemesinden kaynaklanıyor olabilir.

Sol ventrikülün anatomik yapısı ve ölçümleri üzerine geniş sağlıklı popülasyonda çalışmalar yapılmıştır. Bu yapının bozulmasının inme riskini artırabileceği belirtilmesine rağmen prognostik değeri hakkında bilgiler yetersizdir. Sol ventrikül sistol ve diyastol sonu çapının EF ile ilişkili olduğu, düşükEF nin inme şiddetini artırarak kötü prognoza neden olduğu bilinmektedir. Özellikle sol ventrikül fonksiyon bozukluğu ile birlikte çap artışının da olmasının daha değerli olabildiği düşünülmektedir [20, 23]. Bizim çalışmamızda EF değeri ile ilişkisiz olarak sol ventrikül sistol ve diyastol sonu çapının, başlangıç inme şiddeti ile ilişkili olduğu ancak prognoz tayininde kullanılamayacağı gösterilmiştir. Diyastolik posterior duvar, interventriküler septum ve aortik anülüs çapının inme şiddeti ve prognozu ile ilişkili olmadığı görülmüştür.

Sonuç olarak, görülmektedir ki iskemik inme ile kardiyak hastalıklar yakından ilişkilidir.
Sol kalp fonksiyonu ve çaplarının iskemik inme şiddeti ve prognozu ile ilişkili olduğu bilinmektedir. Bu çalışma ile sol ventrikül sistol ve diyastol sonu çapının inme şiddeti ile ilişkili olduğu, çap arttıkça inme şiddetinin arttığı ortaya konulmuştur. TTE bulguları ile prognoz ve hemorajik transformasyon arasında ilişki saptanmamıştır.

Çalışmanın kısıtlılıkları: İskemik inmede aritmiyi dışlamak için 24 saat ritim holter her zaman yeterli değildir. Sol ventrikül fonksiyonlarını belirgin olarak etkileyen hastalıklar dışlanmıştır. Ancak bunlar dışında daha birçok hastalık sol ventrikül fonksiyonlarını etkileyebilmektedir. Hastalara TEE yapılmamış olup intrakardiyak trombüs hakkında bilgi yoktur. Özürlülük ve fonksiyonel durumun değerlendirildiği alt grupların hasta sayısı azdır.

Çıkar ilişkisi: Yazarlar çıkar ilişkisi olmadığını beyan eder.

\section{Kaynaklar}

1. Prevention S. Guidelines for medical treatment for stroke prevention. Ann Intern Med 1994;121:54-55. https://doi.org/10.7326/0003-4819-121-1-19940701000009

2. Chwojnicki K, Ryglewicz D, Wojtyniak B, et al. Acute ischemic stroke hospital admissions, treatment and outcomes in Poland in 2009-2013. Front Neurol 2018;9:134. https://doi.org/10.3389/fneur.2018.00134

3. Adams HP, Bendixen BH, Kappelle LJ, et al. Classification of subtype of acute ischemic stroke. Definitions for use in a multicenter clinical trial. TOAST. Trial of Org 10172 in Acute Stroke Treatment Stroke 1993;24:35-41. https://doi.org/10.1161/01.str.24.1.35

4. Kistler JP. The risk of embolic Stroke-another piece of the puzzle. N Engl J Med 1994;331:1517-1519. https:// doi.org/10.1056/NEJM199412013312211

5. Fralick M, Goldberg N, Rohailla $S$, et al. Value of routine echocardiography in the management of stroke. CMAJ 2019;191:853-859. https://doi. org/10.1503/cmaj.190111

6. Barnes ME, Miyasaka $\mathrm{Y}$, Seward JB, et al. Left atrial volume in the prediction of first ischemic stroke in an elderly cohort without atrial fibrillation. Mayo Clin Proc 2004;79:1008-1014. https://doi.org/10.4065/79.8.1008

7. Powers WJ, Rabinstein AA, Ackerson $T$, et al. Guidelines for the early management of patients with acute ischemic stroke: a guideline for healthcare professionals from the American Heart Association/ American Stroke Association. Stroke 2018;49:46-110. https://doi.org/10.1161/STR.0000000000000158 
8. Williams LS, Yilmaz EY, Lopez Yunez AM. Retrospective assessment of initial stroke severity with the NIH Stroke Scale. Stroke 2000;31:858-862. https:// doi.org/10.1161/01.str.31.4.858

9. Broderick JP, Adeoye O, Elm J. Evolution of the modified Rankin scale and its use in future stroke trials. Stroke 2017;48:2007-2012. https://doi. org/10.1161/STROKEAHA.117.017866

10. Geary L, Hasselström J, Carlsson AC, Eriksson I, von Euler M. Secondary prevention after stroke/transient ischemic attack: a randomized audit and feedback trial. Acta Neurol Scand 2019;140:107-115. https://doi. org/10.1111/ane.13109

11. Go AS, Mozaffarian D, Roger VL, et al. Heart disease and stroke statistics-2013 update: a report from the American Heart Association. Circulation 2013;127:6245. https://doi.org/10.1161/CIR.0b013e31828124ad

12. Modrego PJ, Pina MA, Fraj MM, Llorens N. Type, causes, and prognosis of stroke recurrence in the province of Teruel, Spain. A 5-year analysis. Neurol Sci 2000;21:355-360.

13. Whiteley W, Chong WL, Sengupta A, Sandercock P. Blood markers for the prognosis of ischemic stroke a systematic review. Stroke 2009;40:380-389. https://doi. org/10.1161/STROKEAHA.108.528752

14. Zappasodi F, Croce P, Giordani A, et al. Prognostic value of EEG microstates in acute stroke. Brain Topogr 2017;30:698-710. https://doi.org/10.1007/s10548-0170572-0

15. Bouzas Mosquera A, Broullón FJ, Álvarez García N, et al. Left atrial size and risk for all-cause mortality and ischemic stroke. CMAJ 2011;183:657-664. https://doi. org/10.1503/cmaj.091688

16. Xue J, Lin $Y$, Huang $W$, et al. Left atrial size and risk of recurrent ischemic stroke in a Chinese population. Brain Behav 2017;7:702. https://doi.org/10.1002/ brb3.702

17. Faustino A, Providência R, Barra S, et al. Which method of left atrium size quantification is the most accurate to recognize thromboembolic risk in patients with non-valvular atrial fibrillation? Cardiovasc Ultrasound 2014;12:1-12. https://doi.org/10.1186/1476-7120-1228

18. Jarvie JL, Foody JM. Recognizing and improving health care disparities in the prevention of cardiovascular disease in women. Curr Cardiol Rep 2010;12:488-496. https://doi.org/10.1007/s11886-010-0135-4

19. Charchar FJ, Bloomer LD, Barnes TA, et al. Inheritance of coronary artery disease in men: an analysis of the role of the $Y$ chromosome. Lancet 2012;379:915-922. https://doi.org/10.1016/S0140-6736(11)61453-0
20. Milionis H, Faouzi M, Cordier M, D'AmbrogioRemillard S, Eskandari A, Michel P. Characteristics and early and long-term outcome in patients with acute ischemic stroke and low ejection fraction. Int $\mathrm{J}$ Cardiol 2013;168:1082-1087. https://doi.org/10.1016/j. ijcard.2012.11.036

21. Adeoye AM, Ovbiagele B, Akinyemi JO, Ogah OS, Akinyemi R, Gebregziabher M. Echocardiographic abnormalities and determinants of 1 month outcome of stroke among West Africans in the SIREN study. J Am Heart Assoc 2019;8:010814. https://doi.org/10.1161/ JAHA.118.010814

22. Wouters A, Nysten C, Thijs V, Lemmens R. Prediction of outcome in patients with acute ischemic stroke based on initial severity and improvement in the first 24 h. Front Neurol 2018;9:308. https://doi.org/10.3389/ fneur.2018.00308

23. Choi JY, Cha J, Jung JM, Seo WK, Oh K, Cho KH. Left ventricular wall motion abnormalities are associated with stroke recurrence. Neurol 2017;88:586-594. https://doi.org/10.1212/WNL.0000000000003588

Bu çalışma Ekim 2019'da (3. Ulusal İnme Akademisi Kongresi-Bodrum) e-poster bildirisi olarak sunulmuştur.

Etik onayı: Selçuk Üniversitesi Tıp Fakültesi Klinik Araştırmalar Etik Kurulu'ndan 13.11.2019 tarih ve 2019/325 karar sayısı ile yerel etik onayı alındı.

\section{Yazarların makaleye olan katkıları}

F.E., A.T.Y. çalışmanın ana fikrini ve hipotezini kurgulamışlardır. F.E., G.E., A.D., K.D. teoriyi geliştirmiş ve materyel metod bölümünü düzenlemişlerdir. Sonuçlar kısmındaki verilerin değerlendirmesini F.E., A.T.Y., G.E., A.D., K.D. yapmışlardır. Makalenin tartışma bölümü F.E. ve G.E. tarafından yazılmış, A.T.Y., A.D., K.D gözden geçirip gerekli düzeltmeleri yapmış ve onaylamıştır. Ayrıca tüm yazarlar çalışmanın tamamını tartışmış ve son halini onaylamıştır. 